\title{
Percentual de alunos matrículas com deficiência em classes comuns ou especiais exclusiva no Brasil - 2015 a 2019
}

Percentage of students enrolled with disabilities in common or special classes exclusively in Brazil 2015 to 2019

Porcentaje de estudiantes con discapacidad matriculados en clases comunes o especiales exclusivamente en Brasil - 2015 a 2019

\section{Resumo}

$\mathrm{O}$ artigo teve o objetivo foi fazer um levantamento nas bases de dados do Instituto Nacional de Estudos e Pesquisas Educacionais Anísio Teixeira (INEP) e a Diretoria de Estatísticas Educacionais (DEED sobre número de matrículas de alunos com deficiência, transtornos globais do desenvolvimento ou altas habilidade s em classes comuns ou especiais exclusivas no Brasil entre os anos de 2015 a 2019. Esse levantamento, mostrou que, O número matrículas da educação especial chegou a 1,3 milhão em 2019, um aumento de 34,4\% em relação a 2015, o percentual de alunos com deficiência, transtornos do espectro autista ou altas habilidades matriculados em classes comuns tem aumentado gradualmente para todas as etapas de ensino, verificou-se que o percentual de matrículas de alunos incluídos em classe comum aumentou gradativamente ao longo dos anos. Em 2015, o percentual de alunos incluídos era de 88,4\% e, em 2019, passou para $92,8 \%$, pôr fim a oferta de educação inclusiva por dependência administrativa, foi observado que as redes estaduais $(96,7 \%)$ e municipal $(95,9 \%)$ apresentam os maiores percentuais de alunos. Os dados mostram que os alunos de educação especial estão conseguindo chegar as universidades, estudos do Instituto Nacional de Estudos e Pesquisas Educacionais Anísio Teixeira (INEP) mostra que está ocorrendo aumento nas matrículas de alunos com alguma deficiência nas universidades. Onde, no passado não tinha nenhum aluno em classes comuns nas escolas cursando algum tipo de série.

Palavras-chave: Levantamento de dados; Instituto Nacional de Estudos e Pesquisas Educacionais Anísio Teixeira (INEP); Transtornos globais do desenvolvimento ou altas habilidades.

\begin{abstract}
The article aimed to survey the databases of the National Institute of Educational Studies and Research Anísio Teixeira (INEP) and the Directorate of Educational Statistics (DEED on enrollment of students with disabilities, pervasive developmental disorders or discharge). s skills in common or exclusive special classes in Brazil between the years 2015 to 2019. This survey showed that, The number of enrollments in special education reached 1.3 million in 2019 , an increase of $34.4 \%$ compared to 2015 , the percentage of students with disabilities, autism spectrum disorders or high abilities enrolled in regular classes has gradually increased for all stages of education, it was found that the percentage of enrollments of students included in regular classes increased gradually over the years In 2015, the percentage of students included was $88.4 \%$ and, in 2019 , it rose to $92.8 \%$, finally offering inclusive education for administrative dependence. It was observed that the state $(96.7 \%)$ and municipal $(95.9 \%)$ networks had the highest percentages of students. The data show that special education students are managing to reach universities, studies by the National Institute of Educational Studies and Research Anísio Teixeira (INEP) show that there is an increase in the enrollment of students with a disability in universities. Where, in the past, there were no students in ordinary classes in schools attending some kind of grade.
\end{abstract}

Keywords: Data collection; Instituto Nacional de Estudos e Pesquisas Educacionais Anísio Teixeira (INEP); Global developmental disorders or high abilities.

\section{Resumen}

El artículo tuvo como objetivo relevar las bases de datos del Instituto Nacional de Estudios e Investigaciones Educativas Anísio Teixeira (INEP) y la Dirección de Estadística Educativa (DEED sobre matrícula de estudiantes con discapacidad, trastornos generalizados del desarrollo o egreso). clases especiales en Brasil entre los años 2015 a 2019. Esta encuesta mostró que, el número de inscripciones en educación especial alcanzó 1,3 millones en 2019, un aumento del 34,4\% en 
comparación con 2015, el porcentaje de estudiantes con discapacidades, trastornos del espectro autista o alta Las habilidades matriculadas en clases regulares se han incrementado paulatinamente para todas las etapas de la educación, se encontró que el porcentaje de matrículas de estudiantes incluidos en clases regulares aumentó paulatinamente a lo largo de los años En 2015, el porcentaje de estudiantes incluidos fue 88.4\% y, en 2019, ascendió al 92,8\%, ofreciendo finalmente educación inclusiva para la dependencia administrativa. Se observó que las redes estatales (96,7\%) y municipales $(95,9 \%)$ tuvieron los porcentajes más altos de estudiantes. Los datos muestran que los estudiantes de educación especial están logrando llegar a las universidades, estudios del Instituto Nacional de Estudios e Investigaciones Educativas Anísio Teixeira (INEP) muestran que hay un aumento en la matrícula de estudiantes con discapacidad en las universidades. Donde, en el pasado, no había estudiantes en las clases ordinarias en las escuelas que asistían a algún tipo de grado.

Palabras clave: Recolección de datos; Instituto Nacional de Estudios e Investigaciones Educativas Anísio Teixeira (INEP); Trastornos del desarrollo global o altas capacidades.

\section{Introdução}

As escolas desempenham um papel importante na promoção da aprendizagem dos alunos e no desenvolvimento socioemocional (Crnic \& Neece, 2015). A pesquisa mostra que a educação tem muitos efeitos positivos, como melhores oportunidades educacionais, menos problemas psicológicos, maior bem-estar e melhor saúde física e mental na vida adulta (Dijkstra, 2012). Três fatores importantes para o ajuste psicossocial dos alunos na escola e na vida adulta são as relações sociais dos alunos com professores e colegas e alta autoestima (Hosogi et al., 2012). Especificamente, as relações professor-aluno positivas estão associadas a resultados positivos dos alunos, como o desenvolvimento de habilidades sociais (Cornelius-White, 2007), e relações professor-aluno negativas com resultados indesejáveis, como comportamento perturbador do aluno (Spilt; Koomen; Thijs, 2011). Relacionamentos positivos com os pares fornecem uma importante fonte de apoio social e um contexto no qual os alunos aprendem a gerenciar relacionamentos sociais (Carr, 2006). Relacionamentos negativos com os pares colocam os alunos em risco de desenvolver problemas acadêmicos e dificuldades psicológicas (Carr, 2006). Além disso, a autoestima saudável está, por exemplo, associada à estabilidade psicológica e atividade social positiva e baixa autoestima com isolamento social e depressão (Hosogi et al., 2012).

Um grupo que está particularmente em risco de relacionamentos negativos com professores e colegas e baixa autoestima e, consequentemente, ajuste psicossocial pobre na escola e na vida adulta (Hosogi et al., 2012; Arenare \& Mól, 2020), são alunos com Dificuldades Sócio-Emocionais e Comportamentais (DSEC). Por causa de seus problemas de comportamento, problemas no funcionamento social e desempenho acadêmico prejudicado, eles enfrentam as piores perspectivas de qualquer grupo de alunos durante e após sua carreira escolar (Bradley et al., 2008). Sem intervenção, essas adversidades permanecerão estáveis ou até mesmo se deterioraram com o tempo (Breeman et al., 2006), o que indica que esses alunos estão seriamente em risco.

Em muitos países, pais e escolas podem se inscrever para serviços adicionais de educação especial para esses alunos. Na Holanda, a elegibilidade para serviços de educação especial é determinada por comitês independentes. Posteriormente, os pais e as escolas concordam sobre onde esses serviços de educação especial serão fornecidos. Geralmente, os serviços são prestados aos alunos da própria sala de aula do ensino regular (escola regular) ou os alunos são excluídos do ensino regular e receberão os serviços de educação especial em uma escola exclusiva de educação especial (escola especial).

Pesquisadores e profissionais têm argumentos a favor da inclusão em escolas regulares e a favor de apoio adicional em escolas especiais (Crnic \& Neece, 2015). As razões para a inclusão são que o currículo regular facilita o aprendizado e o aprimoramento de habilidades e que os alunos com DSEC têm amplas oportunidades de aprender com seus encontros sociais com colegas em desenvolvimento típico. Quando os alunos com DSEC, no entanto, precisam de uma abordagem individualizada que uma escola regular não pode oferecer, isso resulta na colocação em uma escola especial. Portanto, na Holanda, os serviços de educação especial fornecidos em escolas especiais são considerados mais abrangentes do que os serviços de educação especial fornecidos em escolas regulares. Especificamente, em escolas especiais, os alunos podem se beneficiar do programa educacional diário mais estruturado que é fornecido, salas de aula menores, o suporte de professores que são treinados para prever, 
compreender e substituir comportamentos perturbadores e inadequados e o suporte profissional e para profissionais que está disponível na escola (Lane et al., 2005). Nessas escolas, no entanto, os alunos com DSEC são cercados por colegas com DSEC, e não sabemos como isso afeta seu desenvolvimento socioemocional. Embora a tendência política internacional nas últimas décadas tenha sido incluir alunos com DSEC na sala de aula regular (Oh-Young \& Filler, 2015), não há acordo sobre qual contexto educacional é melhor para o seu desenvolvimento.

Entretanto, A Lei de Diretrizes e Bases da Educação Nacional (Brasil, 1996) reserva um capítulo para a educação especial. No artigo 59, define e assegura currículo, métodos, recursos e organização específicos para atender às suas necessidades o público dessa modalidade. No início do século seguinte, com a implementação das Diretrizes Nacionais para a Educação Especial na Educação Básica (Brasil, 2001), os sistemas de ensino, por força de lei, deveriam matricular todos os alunos com Deficiência nas escolas comuns, de modo a garantirem o acesso e a permanência desses alunos no ambiente escolar, bem como desenvolver o potencial educativo dessas pessoas.

A constituição a segura o direito de todos à educação está evidenciado nos princípios constitucionais e somente se efetivará em um sistema educacional inclusivo com medidas que ofereçam recursos de acessibilidade na eliminação de barreiras, considerando que as escolas comuns com orientação inclusiva são os meios mais eficazes no combate as atitudes discriminatórias e obtenção de uma real educação para todos (Brasil, 2008; 2015).

Objetivo do trabalho foi fazer um levantamento nas bases de dados do Instituto Nacional de Estudos e Pesquisas Educacionais Anísio Teixeira (INEP) e a Diretoria de Estatísticas Educacionais (DEED sobre número de matrículas de alunos com deficiência, transtornos globais do desenvolvimento ou altas habilidade s em classes comuns ou especiais exclusivas no Brasil entre os anos de 2015 a 2019.

Foram utilizados os dados censo da educação básica 2019 realizado pelo Instituto Nacional de Estudos e Pesquisas Educacionais Anísio Teixeira (INEP) e a Diretoria de Estatísticas Educacionais (DEED).

\section{Metodologia}

O texto está organizado em três partes: Alunos com deficiência, transtornos globais do desenvolvimento ou altas habilidades em classes comuns ou especiais exclusivas segundo etapa de ensino; alunos de 4 a 17 anos de idade com deficiência, transtornos globais do desenvolvimento ou altas habilidades /superdotação que frequentam classes comuns (com e sem atendimento educacional especializado) ou classes especiais exclusivas; alunos com deficiência, transtornos globais do desenvolvimento ou altas habilidades em classes comuns ou especiais exclusivas segundo a dependência administrativa.

\section{Resultados e Discussão}

\section{Alunos com deficiência, transtornos globais do desenvolvimento ou altas habilidades em classes comuns ou especiais exclusivas segundo etapa de ensino}

O número matrículas da educação especial chegou a 1,3 milhão em 2019, um aumento de 34,4\% em relação a 2015. O maior número delas está no ensino fundamental, que concentra 70,8\% das matrículas da educação especial. Quando avaliado o aumento no número de matrículas entre 2015 e 2019, percebe-se que as de ensino médio são as que mais cresceram, um acréscimo de $91,7 \%$ (Figura 1). 
Figura 1. Número de matrículas de alunos com deficiência, transtornos globais do desenvolvimento ou altas habilidades em classes comuns ou especiais exclusivas segundo etapa de ensino - Brasil - 2015 a 2019.

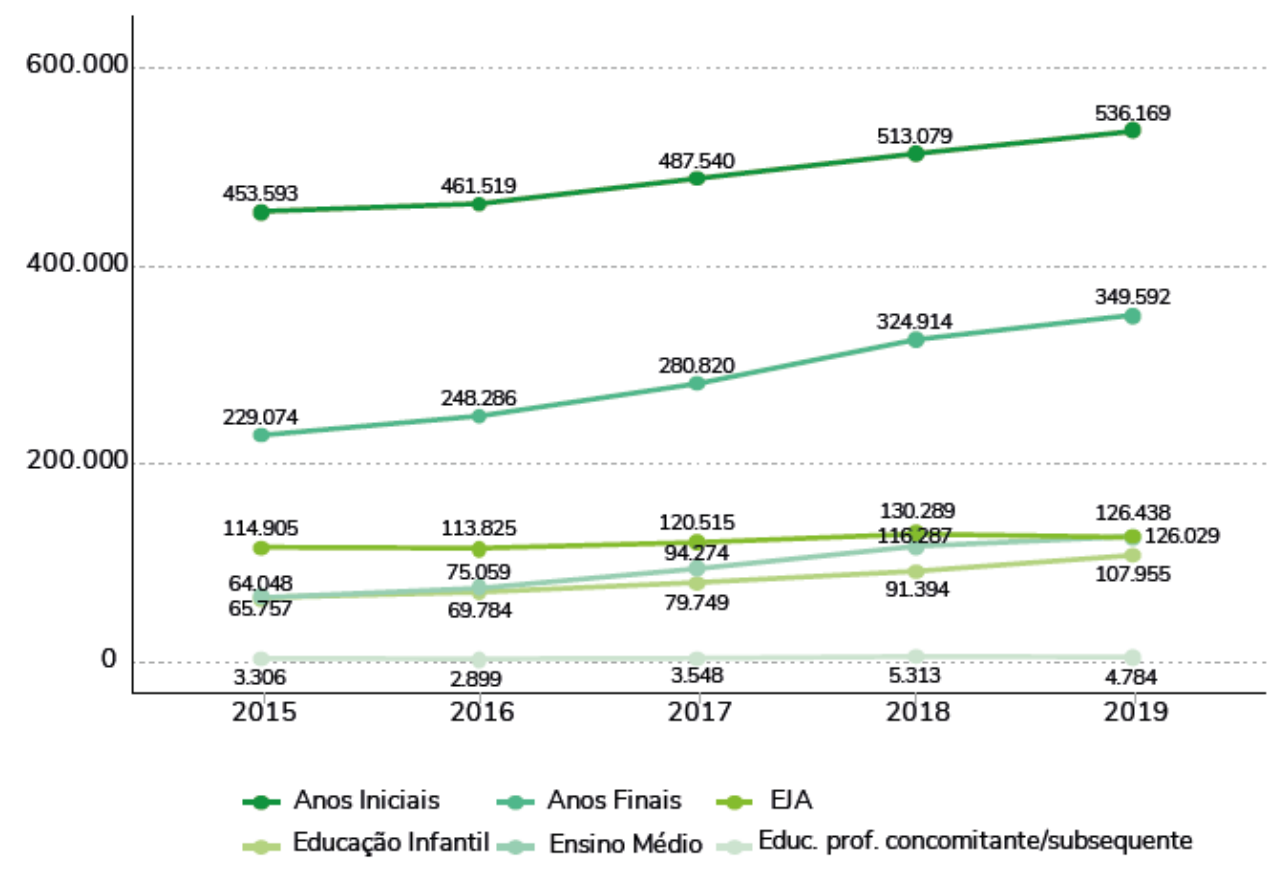

Fonte: Elaborado por Deed/Inep com base nos dados do Censo da Educação Básica 2020 (MEC, 2020).

O percentual de alunos com deficiência, transtornos do espectro autista ou altas habilidades matriculados em classes comuns tem aumentado gradualmente para todas as etapas de ensino. Com exceção da EJA, as demais etapas da educação básica apresentam mais de $89 \%$ de alunos incluídos em classes comuns em 2019. A maior proporção de alunos incluídos é observada no ensino médio e na educação profissional concomitante ou subsequente, com inclusão superior a $99 \%$. O maior aumento na proporção de alunos incluídos, entre 2015 e 2019, foi observado na educação infantil, um acréscimo de 10,8 (Figura 2). 
Figura 2. Percentual de alunos matriculados com deficiência, transtornos globais do desenvolvimento ou altas habilidades que estão incluídos em classes comuns segundo etapa de ensino - Brasil - 2015 a 2019.

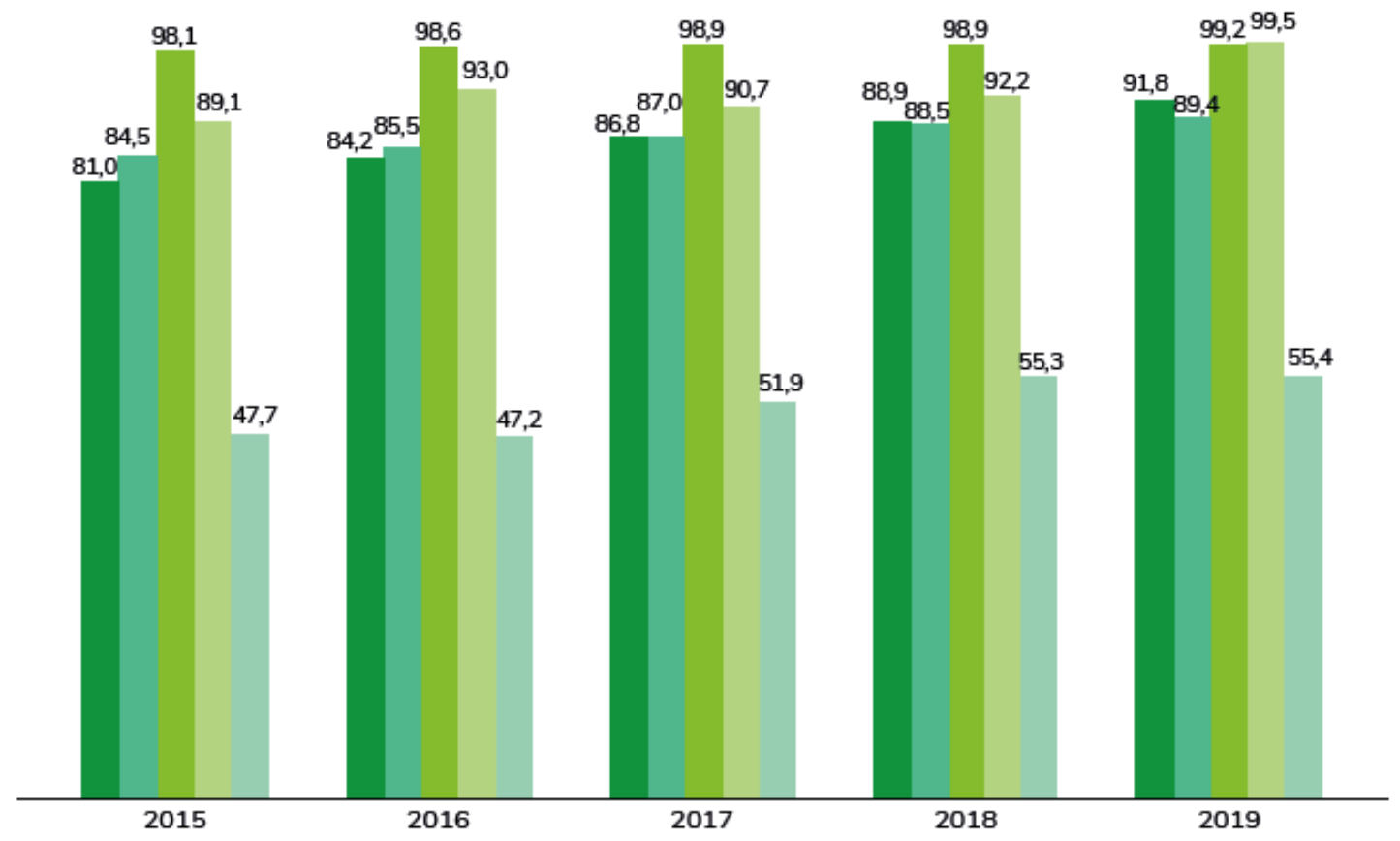

Educação Infantil — Ensino Fundamental — Ensino Médio — Educ. prof. concomitante/subsequente —EA

Fonte: Elaborado por Deed/Inep com base nos dados do Censo da Educação Básica 2020 (MEC, 2020).

Bueno (2004) discute em seu trabalho que a inserção de pessoas com deficiência no âmbito da educação já estivesse ocorrendo há décadas, de forma não gradativa e pouco estruturada, a Declaração de Salamanca acabou por ser tomada como referência pela maioria dos pesquisadores da área de educação especial para a instituição do termo “inclusão escolar”. Pode-se dizer que esse termo se difundiu rapidamente, passando a influenciar a elaboração de políticas públicas e práticas educacionais em inúmeros países.

A Declaração de Salamanca é considerada como um marco na documentação oficial já que reafirmou o compromisso com a educação para todos, conforme a Declaração Universal dos Direitos Humanos; e, ainda, propôs a adoção de linhas de ação em educação especial (Brasil, 2001).

Portanto, a Declaração de Salamanca passou a orientar a reformulação de marcos legais de todos os países, inclusive do Brasil (Kassar, 2004). Com isso, as vozes da educação inclusiva passaram a ressoar em vários novos documentos e decretos, que dispõe sobre a Política Nacional para a Integração da Pessoa Portadora de Deficiência. Também, nos Parâmetros Curriculares Nacionais/PCNs - Adaptações Curriculares: estratégias para a educação de alunos com necessidades educacionais especiais (1999); na Lei no 10.172/01, que aprova o Plano Nacional de Educação; e, ainda, na Resolução CNE/CEB n² 2 , de 11 de setembro de 2001 (Resolução no 2/01), que institui Diretrizes Nacionais para a Educação Especial na Educação Básica (Brasil, 2001).

Entretanto, as Diretrizes Nacionais para Educação Especial na Educação Básica oficializaram no Brasil os termos “educação inclusiva" e "necessidades educacionais especiais". O intuito era de superar o modelo médico baseado no diagnóstico da deficiência em favor de um modelo centrado nas necessidades de aprendizagem. Além disso, passou a regulamentar a organização e a função da educação especial nos sistemas de ensino da educação básica, bem como os locais de atendimento e as propostas de flexibilização e adaptação curricular (Pletsch, 2009; Maia et al., 2020). 
No Brasil, a discussão decorrente dos preceitos da educação inclusiva tem sido assimilada, desdobrada e encaminhada de múltiplas maneiras, carregando sentidos de apropriação e implementação de maneira diversa. Como discute Pletsch (2009), considerando que a concepção da educação inclusiva e inclusão escolar compreendem um sentido amplo, elas têm sido passíveis de inúmeras interpretações, muitas vezes contraditórias.

Carvalho (1997, p. 38) afirmam que a educação inclusiva consiste em um processo de educar, nas escolas de ensino regular, conjuntamente e de maneira incondicional, alunos ditos normais com alunos portadores ou não de deficiência. Essa autora destaca que "a inclusão beneficia a todos, uma vez que sentimentos de respeito à diferença, de cooperação e de solidariedade podem se desenvolver".

Bueno (2004) e Sassaki (1997), todos os alunos devem ter as mesmas oportunidades de frequentar classes comuns do ensino regular. No entanto, ressaltam que, para isso, faz-se necessária uma proposta educacional adequada às especificidades dos alunos. Apontam ainda à necessidade de oferecer suporte aos alunos com deficiência, bem como para os seus professores. Além disso, os autores defendem que as escolas especiais e a formação de pessoal qualificado para esse tipo de trabalho devam ser mantidas, já que certas crianças demandam uma atenção realmente diferenciada. Para eles, nesse caso, a escola especial poderia ser o recurso mais indicado.

\footnotetext{
Alunos de 4 a 17 anos de idade com deficiência, transtornos globais do desenvolvimento ou altas habilidades /superdotação que frequentam classes comuns (com e sem atendimento educacional especializado) ou classes especiais exclusivas

Destaca-se aqui o Plano Nacional de Educação (PNE), cuja Meta 4 se refere à educação especial inclusiva para a população de 4 a 17 anos com deficiência, transtornos do espectro autista ou altas habilidades/superdotação. Observando o gráfico abaixo, verifica-se que o percentual de matrículas de alunos incluídos em classe comum aumentou gradativamente ao longo dos anos. Em 2015, o percentual de alunos incluídos era de 88,4\% e, em 2019, passou para 92,8\%. Além disso, considerando a mesma população de 4 a 17 anos, verifica-se que o percentual de alunos que estão incluídos em classe comum e que têm acesso às turmas de atendimento educacional especializado (AEE) também cresceu no período, passando de 37,4\% em 2015 para 40,8\% em 2019 (Figura 3).
} 
Figura 3. Percentual de matrículas de alunos de 4 a 17 anos de idade com deficiência, transtornos globais do desenvolvimento ou altas habilidades /superdotação que frequentam classes comuns (com e sem atendimento educacional especializado) ou classes especiais exclusivas - Brasil - 2015 a 2019.

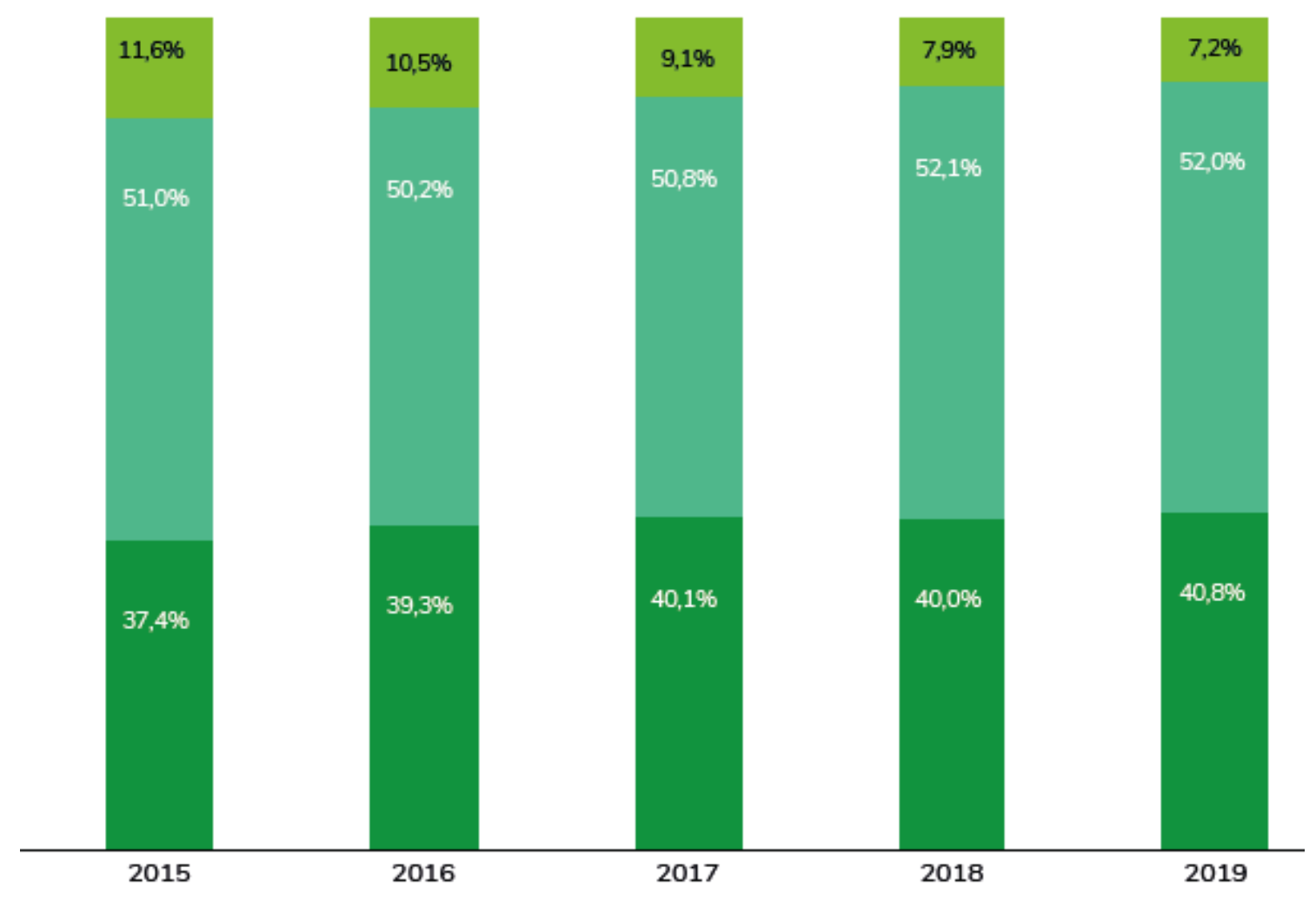

\section{Incluído em classe comum com AEE — Incluído em classe comum sem AEE — Classe especial}

Fonte: Elaborado por Deed/Inep com base nos dados do Censo da Educação Básica 2020 (MEC, 2020).

A legislação sobre a educação especial buscou-se garantir, em diferentes condições e proposições, serviços de apoio pedagógico especializado na escola regular para atender às particularidades do alunado da educação especial. Além disso, evidencia-se a discussão de currículos adaptados e flexibilizados, métodos, técnicas e recursos educacionais específicos, além da terminalidade específica e professores com especialização adequada para o atendimento dos alunos (Brasil \& Seesp, 1998).

A LDBEN 9.394/96, em seu artigo 58, em consonância com a CF/88 indica que, quando necessário, deverá haver serviços de apoio especializado, na escola regular, para atender às peculiaridades dos educandos com necessidades especiais. Afirma ainda que o atendimento educacional será feito em classes, escolas ou serviços especializados, sempre que, em função das condições específicas dos alunos, não for possível a sua integração nas classes comuns do ensino regular.

Carvalho (1997) o apoio especializado, ao contrário do que afirma a lei, deve ser sempre necessário, seja ao próprio aluno, ao seu professor ou à sua família. Sousa e Prieto (2002) discutem que o significado da expressão apoio especializado deve ser definido. E, ainda, afirmam que deve ser explícito quem fará esse atendimento, qual é o papel específico dos professores de educação especial na composição desses serviços e a quem caberá o ônus de sua implantação.

A LDBEN de 1996 já estabelecia que os sistemas de ensino deveriam assegurar professores com especialização adequada em nível médio ou superior, para atendimento especializado, bem como professores do ensino regular capacitados para a integração desses educandos nas classes comuns. Especificamente, os professores especializados deverão desenvolver "competências para identificar as necessidades educacionais especiais para definir, implementar, liderar e apoiar a 
implementação de estratégias de flexibilização, adaptação curricular, procedimentos didáticos pedagógicos e práticas alternativas" (Souza, 2011).

$\mathrm{O}$ aspecto que merece destaque nesse documento é o artigo segundo, o qual atribui à instituição escolar a responsabilidade de organizar-se para o atendimento aos educandos com necessidades educacionais especiais, assegurando as condições necessárias para uma educação de qualidade para todos. Portanto, a autora afirma que a inclusão escolar de pessoas com deficiência, transtornos globais do desenvolvimento e altas habilidades/superdotação no ensino regular requer "uma série de investimentos - equipamentos e, muitas vezes, profissionais especializados não disponíveis na instituição escolar (Pletsch, 2009, p. 29).

\section{Alunos com deficiência, transtornos globais do desenvolvimento ou altas habilidades em classes comuns ou especiais exclusivas segundo a dependência administrativa}

Quando se compara a oferta de educação inclusiva por dependência administrativa, observa-se que as redes estaduais $(96,7 \%)$ e municipal $(95,9 \%)$ apresentam os maiores percentuais de alunos. No entanto, na rede privada, a realidade ainda é diferente: do total de 196.662 matrículas da educação especial, somente 76.874 (39,1\%) estão em classes comuns (Figura 4).

Figura 4. Número de matrículas de alunos com deficiência, transtornos globais do desenvolvimento ou altas habilidades em classes comuns ou especiais exclusivas segundo a dependência administrativa - Brasil - 2019 .

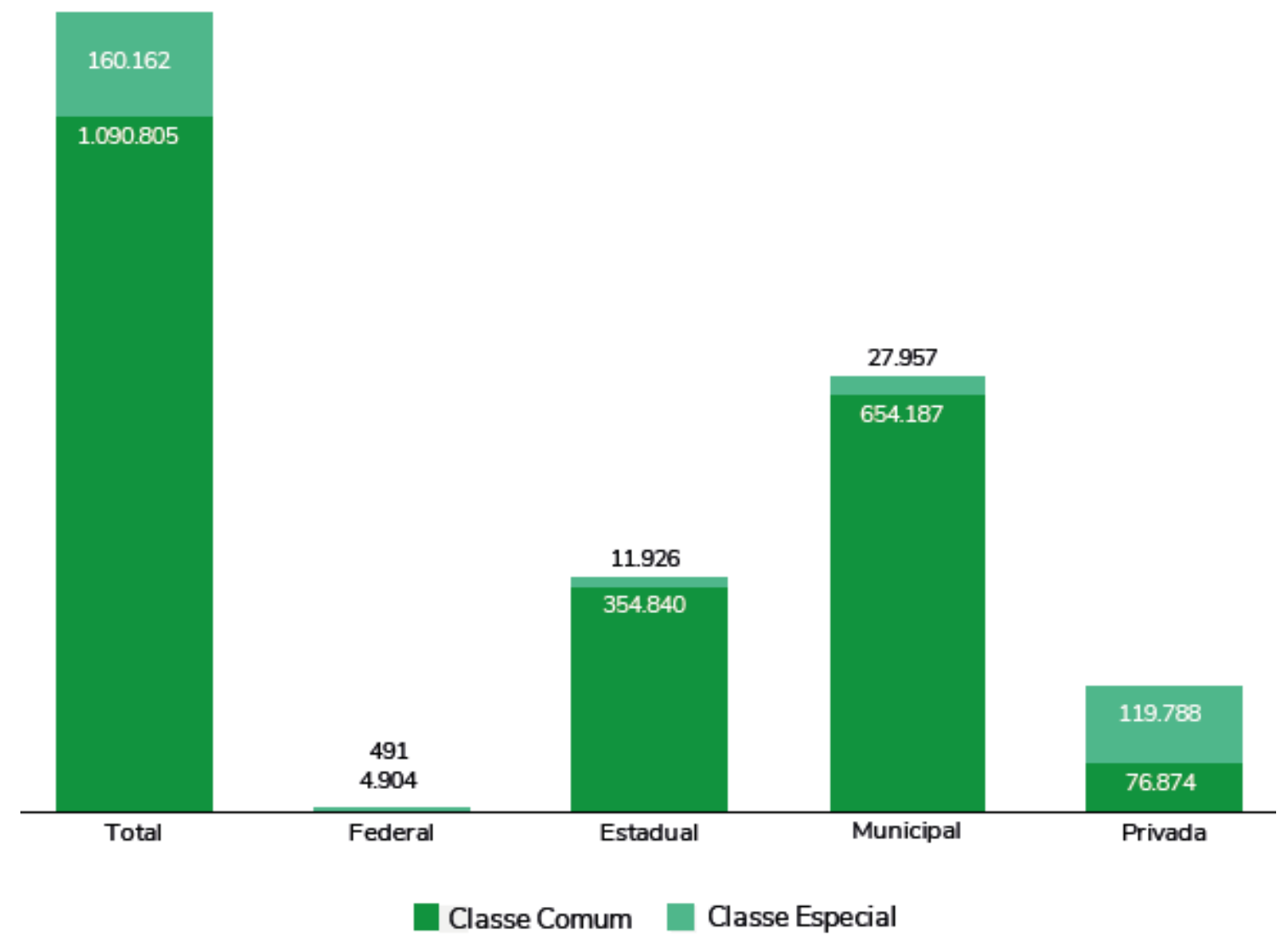

Fonte: Elaborado por Deed/Inep com base nos dados do Censo da Educação Básica 2020 (MEC, 2020).

O crescimento do número de aluno com deficiência matriculados na rede pública municipal impulsionou a necessidade de formação continuada e de outras ações que contribuíram com a expansão da oferta de Educação Especial na Rede Municipal. Rabelo (2011) aponta um crescimento de 22,22\% nas matrículas na Rede Municipal entre os anos de 2007 e 2010, concentrada 
sobretudo na inserção impulsionou a necessidade de formação continuada e de outras ações que contribuíram com a expansão da oferta de Educação Especial na Rede Municipal. Rabelo (2011) aponta um crescimento de 22,22\% nas matrículas na Rede Municipal entre os anos de 2007 e 2010, concentrada sobretudo na inserção.

As Bases da Educação Nacional e a Lei de Diretrizes afirmou o direito de o aluno com deficiência frequentar, preferencialmente, a escola regular. Concernente aos organismos internacionais, o Brasil assumiu as diretrizes da Educação Inclusiva, proclamadas na Declaração de Salamanca (1994) e reafirmadas na Convenção Internacional dos Direitos da Pessoa com Deficiência (ONU, 2007).

De 2003 a 2007, o Programa de educação inclusiva atingiu 5.564 municípios e formou 94.695 entre professores e outros profissionais da educação especial . Pesquisadoras da área analisaram esse Programa e apontaram críticas, tais como: relações de poder entre os sistemas públicos e privados que promovem o atendimento dos alunos da educação especial; ausência de financiamento, o que impossibilita a divulgação do conhecimento por parte das gestoras nos municípios abrangentes; ideias divergentes e conflituosas sobre o conceito de inclusão escolar; dentre outros aspectos (Caiado \& Laplane 2009). No entanto, em 2017, o Programa permanece publicado no site do Ministério, o que sugere sua vigência.

"Portanto, o fluxo escolar indica a progressão de alunos, em determinado nível de ensino, em relação à sua condição de promovido, repetente ou evadido". Optou-se por trabalhar com o fluxo escolar, que, por estar relacionado ao acesso e à permanência na escola, possibilitaria compreender as taxas de transição dos alunos com deficiência na Educação Básica (Alavarse \& Mainardes, 2010, p.1). Sendo que, autores afirmam que Alavarse e MainardeS, 2010, p.1 "o sistema educacional brasileiro costuma ser considerado como um sistema excludente e ineficiente, ou seja, acolhe a maioria da população em idade escolar, mas não garante a todos os alunos a permanência e a progressão no sistema escolar'. Destacando as taxas de transição que abrangem promoção, repetência e evasão, indicando como os alunos transitam de uma série para outra ou de um ano para o outro (Alavarse \& Mainardes, 2010, p.2).

Entretanto, é importante informar que entre os anos de 2009 e 2018 dados do Censo da Educação Superior apontam um aumento de $113 \%$ do número de alunos com deficiência (AcD) matriculados em cursos de graduação. Pois, a Constituição brasileira de 1988, a educação é garantida enquanto direito social, sendo dever do Estado efetivá-la mediante atendimento educacional de preferência na rede regular de ensino às pessoas com deficiência. Diante desse aparato legal, uma série de outros mecanismos foram necessários no sentido de implementar políticas educacionais inclusivas, permitindo o acesso de pessoas com deficiência $(\mathrm{PcD})$ às universidades (Costa \& Oliveira, 2020).

O Instituto Nacional de Estudos e Pesquisas Educacionais Anísio Teixeira (INEP, 2014), nos últimos anos, no Brasil, mostrou através de dados que vem ocorrendo um aumento das matrículas de pessoas com deficiência no Ensino Superior, alcançando 33.337 em 2014. Dessas, 19.654 (58,9\%) em instituições privadas e 13.723 (41,1\%) em instituições públicas de ensino. Do total de estudantes matriculados em instituições públicas, 10.602 (77,3\%) estavam em Instituições Federais, 2.542 $(18,5 \%)$ em Estaduais e 579 (4,2\%) em Municipais.

O Governo Federal criou políticas públicas que favorecem o acesso a esse nível de educação. Destacam-se o Programa de Acessibilidade na Educação Superior que é específico para pessoas com deficiência e que objetivou fomentar a criação e a consolidação de núcleos de acessibilidade com espaços e profissionais qualificados, articulados entre os diferentes órgãos e departamentos das universidades -, o Programa de Apoio a Planos e Reestruturação e Expansão das Universidades Federais REUNI e o Programa Nacional de Assistência Estudantil - PNAES.

Entretanto o ingresso desses alunos especiais não significa que a inclusão de fato está ocorrendo, se torna necessário, portanto, debater sobre os aspectos relacionados a permanência desses estudantes no ambiente universitário, no qual o acesso implica processo de mudança e está relacionado a criar condições legais e direitos igualitários (Manzini, 2008). 


\section{Considerações Finais}

Este estudo mostra que número de matrículas entre 2015 e 2019, do ensino médio são as que mais cresceram, um acréscimo de 91,7\%. Alunos com deficiência em salas comuns são mais de 89\% em 2019. A maior proporção de alunos incluídos é observada no ensino médio e na educação profissional concomitante ou subsequente, com inclusão superior a $99 \%$. Os dados evidência que o Brasil está apresentando uma política pública de inclusão de alunos especiais em acessão, onde tem formado e capacitado profissionais da educação especial.

Os dados mostram que os alunos de educação especial estão conseguindo chegar as universidades, estudos do Instituto Nacional de Estudos e Pesquisas Educacionais Anísio Teixeira (INEP) mostra que está ocorrendo aumento nas matrículas de alunos com alguma deficiência nas universidades. Onde, no passado não tinha nenhum aluno em classes comuns nas escolas cursando algum tipo de série. Hoje já tem alunos nos campos universitários cursando diferentes cursos. Esse avanço se dá por políticas públicas que buscaram inclusão desses alunos no meio estudantil, conforme os Programa de Apoio a Planos e Reestruturação e Expansão das Universidades Federais - REUNI e o Programa Nacional de Assistência Estudantil - PNAES e a LDBEN 9.394/96 e Resolução nº 2/01.

\section{Referências}

Alavarse, O. M., \& Mainardes, J. (2010). Fluxo escolar. In: OLIVEIRA, Dalila Andrade, DUARTE, Adriana Cancella, VIEIRA, Lívia Fraga (Org.). Dicionário de trabalho, profissão e condição docente. FAE-UFMG, 01-04.

Arenare, E. C. C., \& Mól, G. S. (2020). Educação Inclusiva e Deficiência Visual: Mapeamento do Ensino de Química nos Encontros Nacionais de Pesquisa em Ensino de Ciências (ENPECs - 1997-2017). Research, Society and Development, 9(5), e22953047.

Bradley, R., Doolittle, J., \& Bartolotta, R. (2009). Building on the data and adding to the discussion: The experiences and outcomes of students with emotional disturbance. Journal of Behavioral Education, 17, 4-23. https://doi.org/10.1007/s10864-007-9058-6.

Brasil. (2008). Ministério da Educação - Secretaria de Assuntos Estratégicos da Presidência da República - SAE/PR. Reestruturação e Expansão do Ensino Médio no Brasil. Brasília, jul. http://portal.mec.gov.br/seb/arquivos/pdf/2008/interministerialresumo2.pdf.

Brasil. Instituto Nacional de Estudos e Pesquisas Educacionais Anísio Teixeira - INEP/MEC/DAEB. Relatório Pedagógico: ENEM 2011-2012. INEP, 2015. http://portal.inep.gov.br/documents/186968/484421/Relat\%C3\%B3rio+Pedag\%C3\%B3gico+Enem+2011-2012/b29257e3-2a6c-44a3-992a-

02130c379ba9?version=1.1.

Brasil. Lei $\mathrm{n}^{\circ}$ 10.172, de 9 de janeiro de 2001. Plano Nacional de Educação - PNE (2001-2010). Presidência da República - Casa Civil. http://www.planalto.gov.br/ccivil_03/leis/leis_2001/110172.htm..

Brasil. Lei no 9.394, de 20 de dezembro de 1996. Estabelece as Diretrizes e Bases da Educação Nacional. Diário Oficial da República Federativa do Brasil, Brasília, DF, 20 dez.1996. http://www.planalto.gov.br/ccivil_03/Leis/L9394.htm>.

Brasil. MEC. (1998). Ministério da Educação e do desporto. Secretaria de Educação Especial. Parâmetros Curriculares Nacionais: adaptações curriculares: Estratégias para a educação de aluno com necessidades educacionais especiais. Brasília: MEC/SEF/SEESP.

Breeman, L. D., Van lier, P. A. C., Wubbels, T., Verhulst, F. C., Van Der Ende, J., Maras, A., Hopman, J. A. B., \& Tick, N. T. (2006). Developmental links between disobedient behavior and social classroom relationships in boys with psychiatric disorders in special education. https://doi.org/10.1007/s10802-0149935-0.

Bueno, J. G.S. (2004). Educação especial brasileira: integração/segregação do aluno diferente. EDUC, 2004.

Caiado, K. R. M., \& Laplane, A. L. F. (2009). Programa Educação Inclusiva: Direito à Diversidade - uma análise a partir da visão de gestores de um município pólo. Educação e Pesquisa (USP. Impresso), 35(2), 303-315.

Carr, A. (2006). Normal development. In A. Carr (Ed.). The handbook of child and adolescent clinical psychology, p. 3-39. Routledge Taylor \& Francis Group.

Carvalho, R. E. (1997). A nova LDB e a educação especial. WVA.

Cornelius-White, J. (2007). Learner-centered teacher-student relationships are effective: A meta-analysis. Review of Educational Research, 77, 113-143.

Costa, L. R. F, \& Oliveira, M. L. (2020). Programa de Apoio ao Estudante com Deficiência: inclusão e permanência de PcD na Universidade Federal da Paraíba. Educação [recurso eletrônico]: dilemas contemporâneos: volume IV / Organizador Lucas Rodrigues de Oliveira. - Nova Xavantina, MT: Pantanal, p, 124.

Crnic, K., \& Neece, C. Socioemotional consequences of illness and disability. In R. M. Lerner, M. E. Lamb (Eds.), Handbook of child psychology and developmental science, volume 3, socioemotional processes, (7a ed.), 287-323. 
Research, Society and Development, v. 11, n. 1, e23011124763, 2022

(CC BY 4.0) | ISSN 2525-3409 | DOI: http://dx.doi.org/10.33448/rsd-v11i1.24763

Dijkstra, A. B. Sociale opbrengsten van onderwijs [Social returns of education]. (Oratiereeks). Vossiuspers UvA https:// pure.uva.nl/ws/files/1615318/122688_PDF_7303Dijkstra_webver sie.pdf, 2012.

Hosogi, M., Okada, A., Fujii, C., Noguchi, K., \& Watanbe, K. (2012). Importance and usefulness of evaluating self-esteem in children. Biopsychosocial Medicine, 6(9), 1-6. https://doi.org/10.1186/1751-0759-6-9.

Instituto Nacional de Estudos e Pesquisas Educacionais Anisio Teixeira (2014). Sinopses estatísticas da educação superior - graduação: censo da educação superior de 2014. http://portal.inep.gov.br/superior-censosuperior-sinopse

Kassar, M. C. M. (2004). Matrícula de Crianças com Necessidades Educacionais Especiais na rede de Ensino Regular. In: GÓES, Maria Cecília Rafael de. LAPLANE, Adriana Lia Friszman de. (Orgs). Políticas e Práticas de Educação Inclusiva. Campinas, SP: Autores Associados.

Lane, K. L., Wehby, J. H., Little, M. A., \& Cooley, C. (2005). Academic, social, and behavioral profiles of students with emotional and behavioral disorders educated in self-contained classrooms and self-contained schools: Part I-Are they more alike than different? Behavioral Disorders, 30(4), 349-361. http://www.ccbd.net/.

Maia, S. D. B., Souza, C. J. F, \& Ferreira, L. F. (2020).Transtorno do Desenvolvimento da Coordenação sob a luz da Educação Inclusiva e dos Direitos Humanos. Research, Society and Development, 9(9), e869998059.

Manzini, E. J. (2008). Acessibilidade: um aporte na legislação para o aprofundamento do tema na área de educação. In: Manzini EJ et al. (Org.). Educação Especial: Diálogo e Pluralidade. Ed. Mediação.

Ministério Da Educação (MEC), Instituto Nacional de Estudos e Pesquisas Educacionais Anísio Teixeira (INEP) e Diretoria de Estatísticas Educacionais. Censo escolar de 2020. Brasília, 29 de janeiro de 2021.

Oh-Young, C., \& Filler, J. (2015). A meta-analysis of the effects of placement on academic and social skill outcome measures of students with disabilities. Research in Developmental Disabilities, v.47, p.80-92. https://doi.org/10.1016/j.ridd.2015.08.014.

Organização das Nações Unidas (ONU) - Declaração dos Direitos Humanos, 2007. <www.dhnet.org.br>.

Pletsch, M. D. (2009). Repensando a inclusão escolar de pessoas com deficiência mental: diretrizes políticas, currículo e práticas pedagógicas. $2009.254 \mathrm{f}$. Tese (Doutorado em Educação) - Universidade do Estado do Rio de Janeiro..

Rabelo, A. S. (2011). Os impactos da política de atendimento educacional especializado: análise dos indicadores educacionais de matrículas de alunos com deficiência. 2011. (Dissertação de Mestrado). Universidade Federal de Mato Grosso do Sul, Campo Grande, Mato Grosso do Sul, Brasil.

Sassaki, R. (1997). Inclusão. Construindo uma sociedade para todos. WVA.

Sousa. S. Z. L., \& Prieto, R.G. (2002). A educação especial. In: Oliveira, R.P. e Adrião, T. (Orgs.). Organização do ensino no Brasil. Xamã, 123-136.

Souza, P.M. (2011). Identificação e caracterização dos alunos com deficiência, transtornos globais do desenvolvimento e altas habilidades/superdotação, matriculados nas classes comuns do ensino regular, na rede pública estadual, em município do interior paulista. 2011. 123 f. Dissertação (Mestrado em Ciências, Área: Psicologia.) - Faculdade de Filosofia, Ciências e Letras de Ribeirão Preto da USP, São Paulo.

Spilt, J. L., Koomen, H. M. Y., \& Thijs, J. T. (2011). Teacher wellbeing: The importance of teacher-student relationships. Educational Psychology Review, 23, 457-477. https://doi.org/10.1007/s10648-011-9170-y. 